\title{
The Coronavirus
}

Nonstructural Proteins

\author{
T. D. K. BROWN AND I. BRIERLEY
}

\section{INTRODUCTION}

The definition of a group of virus-coded proteins/polypeptides, the nonstructurals, as those not found in virions is crude, but has some merit in that it immediately focuses attention on the potential difficulties encountered in defining them. It leaves aside the practical difficulties implicit in attempting to detect small amounts of virus-coded polypeptides, particularly if they are of low molecular weight, which may be present in virions, and, on the other hand, in deciding whether or not such polypeptides, if detected, are present adventitiously. This chapter will thus consider currently available information relating to coronavirus polypeptides (or predicted polypeptides) other than those routinely present in the virions of all coronaviruses subjected to detailed analysis, i.e., the spike glycoprotein (S), the integral membrane glycoprotein $(M)$, the small-membrane protein $(\mathrm{sM})$, and the nucleocapsid protein $(\mathrm{N})$, or present in only some coronaviruses, i.e., the hemagglutinin esterase (HE) glycoprotein.

A brief consideration of the range of methods that have been employed to detect nonstructural proteins in virus-infected cells and the limitations of such methods is relevant to an analysis of available data on coronavirus nonstructural proteins. Prior to the introduction of techniques for molecular cloning, only a limited number of approaches were available for detecting nonstructural polypeptides. The most obvious of these was the detection, using radiolabeling techniques, of products absent from virions but present in infected cells. The success of this type of approach is dependent in part on the efficiency of host

T. D. K. BROWN AND I. BRIERLEY - Virology Division, Department of Pathology, Cambridge University, Cambridge CB2 1QP, England.

The Coronaviridae, edited by Stuart G. Siddell, Plenum Press, New York, 1995. 
cell shutoff; this is frequently inefficient in coronavirus-infected cells. The in vitro translation of purified virus mRNAs provided a potential alternative approach to identification of virus-coded polypeptides not present in virions. Assay of enzymatic activity predicted to be associated with a nonstructural protein, e.g., virus-coded RNA-dependent RNA polymerase activity, is also possible. These approaches have been applied with varying success to coronaviruses.

The prospects for analyzing nonstructural proteins were dramatically improved by the advent of molecular cloning techniques and consequent ease of sequence determination. The cloning and sequencing of coronavirus cDNAs has revealed substantial numbers of open reading frames (ORFs) in the unique regions of virus mRNAs known not to be involved in the synthesis of virion proteins. In most cases, no candidate product of these ORFs had previously been detected in infected cells. Cloned sequences can be employed to develop reagents for the detection of putative nonstructural proteins coded by the ORFs; production of monospecific antisera is particularly valuable in this context.

Detection is, however, only an initial, albeit essential, step in the characterization of nonstructural proteins. A range of functional studies are ultimately required for an understanding of the roles of these proteins; such studies have scarcely been started for coronaviruses. We are thus, at the present time, aware of the existence of a substantial number of ORFs potentially coding for nonstructural polypeptides without, in most cases, significant insights into their functions other than those which can be gained by more-or-less sophisticated computer-based sequence analyses.

The minimum function (RNA-dependent RNA synthesis) of the nonstructural proteins encoded by mRNA 1 (genomic/virion RNA) is defined by its infectivity (Lomniczi and Kennedy, 1977; Schochetman et al., 1977); this makes it unique among coronavirus nonstructural proteins. For this reason the products encoded by mRNA ls will be considered together for all coronaviruses; other ORFs for which no such unifying knowledge of function exists will be considered on the basis of individual viruses or groups of related coronaviruses.

\section{PRODUCTS OF mRNA 1}

\section{A. Sequence Analysis of the Unique Regions of mRNA 1s}

\section{General Analysis}

Four complete sequences of RNA 1 unique regions are currently available: those of avian infectious bronchitis virus (IBV) strain Beaudette, murine hepatitis virus (MHV) strains JHM and A59, and human coronavirus (HCV) strain $229 \mathrm{E}$. Sequencing of the putative unique region of mRNA 1 of IBV represented in 17 overlapping cDNA clones (Boursnell et al., 1987) provided the first convincing evidence that this region of the coronavirus genome had an extremely large coding capacity (approximately $20 \mathrm{~kb}$ in the case of IBV) and that it contained two overlapping ORFs (la and $\mathrm{lb}$ ) capable, in the case of IBV, of coding 
for polypeptides of 441,000 and 300,000 , Da respectively. The downstream $1 \mathrm{~b}$ ORF was found to be in the -1 frame with respect to the upstream la ORF. There was a 42-nucleotide overlap between the ORFs. The implication was that coronavirus polymerases were likely to be complex and that their components might be expressed by an unusual mechanism.

The unique region of RNA 1 of MHV strains JHM and A59 were subsequently cloned and sequenced; they are approximately 22-kb long and again were found to contain two overlapping ORFs (la and lb) (Baker et al., 1989; Bonilla et al., 1994; Bredenbeek et al., 1990b; Lee et al., 1991; Pachuk et al., 1989; Soe et al., 1987). The relationship between the la and lb ORFs is similar to that seen in IBV; the lb ORF is in the -1 frame with respect to la and there is a 75nucleotide overlap between them. Attention has been drawn to apparent minor errors in the published sequence of MHV-JHM and also to a region of genuine heterogeneity detected also in MHV-2 (Bonilla et al., 1994).

The cloning and sequencing of the HCV 229E mRNA 1 unique region has also been reported (Herold et al., 1993). Again it was found to be large (approximately $20 \mathrm{~kb}$ ) and to contain two overlapping reading frames with the $1 \mathrm{~b}$ ORF being in the -1 frame with respect to the la ORF and overlapping it by 43 nucleotides. A summary of the major features of the available mRNA 1 unique region sequences are presented in Table I.

The overall relationships between the amino acid sequences of the predicted products of the la and lb ORFs have been determined by computer analysis (summarized in Table I). It is clear that the $\mathrm{lb}$ ORF is much more highly conserved than the la ORF, and that within la the greatest divergence is seen at the amino-terminus. The substantial additional sequences present in MHV la, but not in IBV 1a, are found at the 5' end (Bredenbeek et al., 1990b; Herold et al., 1993; Lee et al., 1991; Pachuk et al., 1989; Soe et al., 1987). The high degree of amino acid sequence conservation in $\mathrm{lb}$ is also indicated by the limited data available for porcine transmissible gastroenteritis virus (TGEV), feline infectious peritonitis virus (FIPV), and canine coronavirus (CCV). This high degree of conservation is in marked contrast to that observed for other coronavirus nonstructural proteins (see Sections III to X).

TABLE I. Summary of the Features of Sequenced mRNA 1 Unique Regions ${ }^{a}$

\begin{tabular}{lcccc}
\hline & IBV Beaudette & MHV-JHM & MHV A59 & HCV 229E \\
\hline Length of la ORF (aa) & 3951 & 4488 & 4468 & 4085 \\
Length of lb ORF (aa) & 2691 & 2731 & 2733 & 2686 \\
Length of la/lb fusion (aa) & 6629 & 7203 & 7176 & 6758 \\
la/lb Overlap (nt) & 42 & 75 & 75 & 43 \\
la Amino acid identity to IBV (\%) & $(100)$ & 29 & 29 & 27 \\
la Amino acid similarity to IBV (\%) & $(100)$ & 52 & 52 & 51 \\
lb Amino acid identity to IBV (\%) & $(100)$ & 56 & 57 & 54 \\
lb Amino acid similarity to IBV (\%) & $(100)$ & 72 & 72 & 70 \\
\hline
\end{tabular}

${ }^{a}$ Data obtained from published sequences using the GCG GAP program with default settings.

based on simultaneous slippage model of Brierley et al. $(1987,1989,1992)$. 


\section{Motif Analysis}

Computer-based motif analyses, in the absence of substantial efforts to obtain experimental data, have been extensively applied to the nucleotide sequences of the mRNA 1 unique regions and to the amino acid sequences derived from them. Initial analyses of the IBV sequence demonstrated amino acid homologies in the lb ORF with RNA-dependent RNA polymerase-related polypeptides of Sindbis virus, an alphavirus, and brome mosaic virus, a tricornavirus; these lay between amino acids 1200 and 1500 (Boursnell et al., 1987). More sophisticated analyses of the la and $1 \mathrm{~b}$ ORFs were subsequently carried out (Gorbalenya et al., 1988a,b, 1989b; Hodgman, 1988). The homologies detected by Boursnell et al. (1987) were confirmed and their relationships extended using sequences from a wide range of RNA viruses. It was suggested that they included an nucleoside triphosphate (NTP) binding domain characteristic of helicases.

Other motifs characteristic of positive-strand virus RNA-dependent RNA polymerases were also detected. The most "obvious" of these was the cryptic GDD motif present in the IBV sequence as SDD. A region with extremely high homology to potyvirus polymerases is noteworthy. Various other features were identified in the la and lb ORFs. These included a potential zinc finger nucleic acid binding domain in $1 \mathrm{~b}$, a homologue of the $3 \mathrm{C}$ protease of picornaviruses in la, and 13 putative $Q / G, S$ target sites distributed in both la and $1 b$. Homology to a fragment of the catalytic center of another class of cysteine protease from Streptococcus pneumoniae (SPL protease) was detected in la. Attention was also drawn to a possible growth factor-related domain and two potential membrane spanning regions in la.

The availability of the IBV sequence and the analytical abilities of the Russian group laid the foundations for the dissection of other coronavirus mRNA 1 sequences as they became available. The possibilities for both narrow and broad phylogenetic comparisons are now more extensive and it is possible to consider the features of a core set of coronavirus mRNA 1 motifs, to which putative functions can be ascribed, and their relationships to both viral and cellular homologues. Those currently identified are: in la (1) a papainlike cysteine protease domain(s), (2) a chymotrypsin/picornaviral 3C proteaselike domain, and (3) a cysteine-rich growth factor-related domain; and in $1 \mathrm{~b}(4)$ a classical positive-strand RNA-dependent RNA polymerase domain, (5) a zinc finger nucleic acid binding domain, and (6) an NTP binding/helicase domain. To this list it is perhaps reasonable to add the conserved membrane spanning domains. The locations of these motifs/domains are presented in Fig. 1 and Table II.

\section{a. Papainlike Cysteine Protease Domains}

Viral homologues of the classical papainlike proteases (PLP) were first identified in poty- (Oh and Carrington, 1989) and alphaviruses (Hardy and Strauss, 1989; Strauss et al., 1992). The identities of their putative active site cysteine and histidine residues were confirmed by site-directed mutagenesis. 


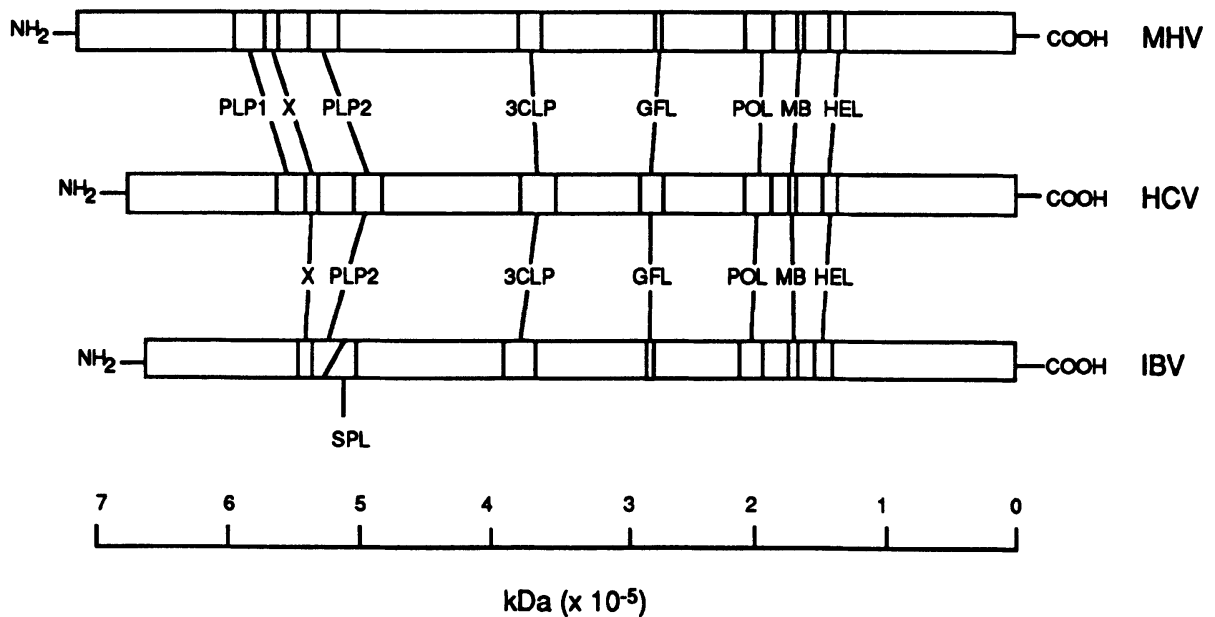

FIGURE 1. The positions of motifs identified in the predicted polypeptide sequence of the $1 \mathrm{a} / \mathrm{b}$ polyprotein encoded by the mRNA 1 unique regions of IBV, MHV, and HCV are shown. PLP = papain-like protease, $3 \mathrm{CLP}=3 \mathrm{C}$-like protease, $\mathrm{GFL}=$ growth factor-like, $\mathrm{POL}=\mathrm{RNA}$-dependent RNA polymerase, $\mathrm{MB}=$ metal binding, $\mathrm{HEL}=$ helicase. The data are from computer assisted analyses (Gorbalenya et al., 1989; Lee et al., 1991; Herold et al., 1993).

Homologues were subsequently identified in coronaviruses (Gorbalenya et al., 1989b; Herold et al., 1993; Lee et al., 1991). Two PLP domains are present in both MHV and HCV, but only one is present in IBV. The IBV domain lies upstream of and overlaps the SPL protease domain. The role of the upstream PLP (PLP1) domain in the cleavage of $\mathrm{p} 28$ from the amino-terminus of MHV la has been demonstrated (Baker et al., 1989, 1993). It has been suggested that this PLP

TABLE II. Positions of Motifs within the Predicted Amino Acid Sequences of mRNA la and b ORFs ${ }^{a}$

\begin{tabular}{cccc}
\hline & IBV & MHV-JHM & HCV \\
\hline ORF 1a & & & \\
PLP1 & - & $1100-1349$ & $1041-1234$ \\
PLP2 & $1236-1497$ & $1696-1953$ & $1688-1886$ \\
SPL & $1385-1677$ & - & - \\
3CLP & $2811-2943$ & $3382-3517$ & $2965-3268^{b}$ \\
GFL & $3894-3917$ & $4446-4468$ & $3933-4069^{b}$ \\
ORF 1b & & & \\
POL & $588-818$ & $560-852$ & $534-836$ \\
MB & $931-1005$ & $942-1015$ & $924-999$ \\
HEL & $1209-1500$ & $1217-1506$ & $1202-1330$ \\
\hline
\end{tabular}

${ }^{a}$ Based on data from Gorbalenya et al. (1988a,b, 1989a, b, 1991), Herold et al. (1993), Koonin (1991), and Lee et al. (1991).

${ }^{b}$ Boundaries of predicted processed polypeptide-containing motif rather than those of motif itself (based on assumptions about targets for the 3CLP). 
domain is particularly closely related to the leader protease of foot-and-mouth disease virus (FMDV) (Gorbalenya et al., 1991). There are no data available on the role of the downstream PLP domain (PLP2) of MHV. There are similarly no published data on the role of either of the PLP domains of HCV 229E or of the single PLP domain of IBV. The IBV PLP is homologous to the downstream PLP2 domains of MHV and HCV.

It is interesting that the arteriviruses, which contain a subset of the coronavirus polymerase sequences in their mRNA 1 unique regions, encode a PLP domain in a vestigial la ORF and that it cleaves la to generate a $30-\mathrm{kDA}$ polypeptide. The cleavage is, however, downstream of the PLP domain (Snijder et al., 1992). Attention has also been drawn to a region highly conserved between IBV and MHV, the so-called X domain, which is present immediately upstream of the IBV PLP domain but immediately downstream of the MHV PLP1 domain. A related domain has been detected close to the thiol protease domains of alpha- and rubiviruses (Gorbalenya et al., 1991).

\section{b. Chymotrypsin/Picornaviral 3C-like Protease Domains}

The chymotrypsin/picornaviral 3C-like protease (3CLP) domains of approximately 300 amino acids with homologies to proteases identified in picorna-, como-, nepo-, poty-, sobemo-, and luteoviruses are present in the $3^{\prime}$ region of the 1a ORFs of IBV, MHV, and HCV. The proposed catalytic histidine and cysteine residues initally identified in IBV are present in MHV and HCV (Herold et al., 1993; Lee et al., 1991). Unusual features of the coronavirus 3CLPs include, first, the lack of conservation in MHV and HCV of what appeared to be a conserved, catalytically active acidic residue in IBV and other viral 3CLPs (Gorbalenya et al., 1989b), and, second, the substitution of coronavirus sequences of tyrosine for the conserved glycine normally seen in the putative 3CLP active site substrate binding region (Herold et al., 1993; Lee et al., 1991). Attempts have been made to predict cleavage sites for the putative 3CLP, based largely on studies of picornaviral enzymes; the cleavages occur primarily at Q,E/G,S,A but are selective, and the basis for the selectivity is unclear. Gorbalenya et al. (1989) derived a consensus sequence for IBV including $Q / S$ or $\mathrm{G}$ using approaches based on comparison of sequences surrounding the $\mathrm{Q} / \mathrm{S}$ and $\mathrm{Q} / \mathrm{G}$ sites flanking putative functional domains. Further potential cleavage sites conforming to the consensus were then identified; a total of 13 sites was reported. It was suggested that a significant feature of the consensus was the presence of a hydrophobic residue at -1 , which is a general feature of 3 CLP target sequences. The sites flanking the 3CLP domain both had a positively charged residue at -3 . Conservation of at least some of these potential cleavage sites has been observed in MHV and HCV (Herold et al., 1993; Lee et al., 1991). The membrane domains flank the 3CLP domain.

\section{c. Cysteine-Rich Growth Factor-Related Domains}

This type of sequence is found in the predicted la polypeptide sequences of IBV, MHV, and HCV (Gorbalenya et al., 1989b; Herold et al., 1993; Lee et al., 
1991). It is clear that it is exceptionally cysteine-rich, but its relationship to growth factors may be distant and evidence of functional relationships to growth factors is lacking.

\section{d. RNA-Dependent RNA Polymerase Domains}

The amino acid sequence relationships between positive-strand virus RNA-dependent RNA polymerases are well established (Argos, 1988; Koonin, 1991). Notable features include the high degree of conservation of this region between IBV, MHV, and HCV, in particular the finding that the coronavirus sequences all contain an SDD motif rather than the classical GDD motif. No evidence for a second polymerase domain has been obtained.

\section{e. Zinc Finger Nucleic Acid-Binding Domain}

This domain, characterized by the presence of a defined series of histidine and cysteine residues, is again clearly conserved in the three coronavirus $\mathrm{lb}$ sequences; but some of the structural features proposed on the basis of the IBV sequence cannot be present in the MHV or HCV polypeptides. Evidence for metal binding has yet to be obtained.

\section{f. NTP Binding/Helicase Domain}

The homology between this region of the coronavirus genome and sequences present in other positive-strand RNA viruses was detected in initial analyses of the IBV sequence, but its significance was not appreciated until the work of Gorbalenya and Koonin (Gorbalenya et al., 1988a,b, 1989a,b). Not surprisingly, the domain is well conserved in MHV and HCV.

\section{B. Expression of the la and $1 \mathrm{~b}$ ORFs in Vitro}

Cell-free approaches have been used to analyze the translation of genomic RNA/mRNA 1 . The translation of both genomic RNA preparations and in vitro transcripts prepared from cloned cDNAs has been studied. Virion RNA of MHV was translated in rabbit reticulocyte lysate (RRL) with the production of three structurally related polypeptides of molecular weight greater than $200 \mathrm{kDa}$ (Leibowitz et al., 1982). A series of minor products of lower molecular weight could also be discerned. These observations have been extended in a number of ways (Denison and Perlman, 1986). A series of products were detected in RRL translations with two quantitatively significant products with molecular weights greater than $200 \mathrm{kDa}$ being emphasized (p220 and p250). A well-defined product of low molecular weight was characterized. It was demonstrated to be $\mathrm{N}$-terminal and to be generated by proteolytic cleavage from a relatively large precursor. The precursor-product relationships of $\mathrm{p} 28$ and the discrete highmolecular-weight products was not however completely clarified. The inhibitory effects of leupeptin, a reversible inhibitor of trypsinlike serine/cysteine 
proteases, and $\mathrm{ZnCl}_{2}$ on $\mathrm{p} 28$ cleavage were demonstrated. Both these studies were carried out prior to the publication of the IBV polymerase sequence (Boursnell et al., 1987), which revealed for the first time the potential complexity of the coronavirus polymerase "problem."

The observations of Denison and Perlman (1986) were extended by Soe et al. (1987) using in vitro translation of in vitro transcripts prepared from the $5^{\prime}$-most $2 \mathrm{~kb}$ of the MHV genome. They confirmed the N-terminal location of p28. They also demonstrated that deletion of sequences upstream of the potential initation codon at position 215 increased the efficiency of translation in $\mathrm{RRL}$ of in vitro transcripts derived from the $2 \mathrm{~kb}$ fragment. It was suggested that the low levels of translation observed when the 5' untranslated region (UTR) is intact result from the presence of highly stable RNA secondary structures. The work on MHV was extended (Baker et al., 1989) with the demonstration that sequences involved in the cleavage of p28 were located between 3.9 and $5.3 \mathrm{~kb}$ from the $5^{\prime}$ end of the MHV genome and the observation that the protease was active only in cis. Following the identification of two PLP domains in the MHV la sequence (Lee et al., 1991), a more detailed examination of the sequences responsible for the cleavage of p28 was carried out (Baker et al., 1993). The catalytic functions of the putative active site cysteine and histidine residues of PLP2 identified by computer-based analysis were confirmed by site-directed mutagenesis. Its activity was shown to be sensitive to the deletion of at least some of the polypeptide sequences between it and the $\mathrm{N}$-terminal target site.

In vitro translation of MHV genomic RNA has been used to study processing of the polypeptide sequences encoded by the lb ORF (Denison et al., 1991). A series of polypeptides recognized by antisera raised against the carboxyterminus of ORF $1 \mathrm{~b}$ were identified. Leupeptin, in contrast to its effect on $\mathrm{p} 28$ cleavage, did not alter the pattern of cleavage observed for the $1 \mathrm{~b}$ products, thus providing preliminary evidence for a role for at least two proteolytic activities in the cleavage of the MHV gene 1 polypeptides. It proved impossible, however, to align convincingly the cleavage products (apparent molecular weights, 90, $74,53,44$, and $32 \mathrm{kDa}$ ) with predicted 3CLP cleavage sites in $1 \mathrm{~b}$.

An important question that arose following completion of the sequence of IBV was the mechanism by which ORF $1 \mathrm{~b}$ is expressed, since it overlaps $1 \mathrm{a}$ by 42 nucleotides and is in the -1 reading frame with respect to la. A number of observations raised the possibility that $\mathrm{lb}$ may be expressed as a fusion protein with the upstream la ORF following a -1 ribosomal frameshift at the overlap region of the two ORFs (Boursnell et al., 1987). First, the 70 or so bases preceding the first AUG codon of $1 \mathrm{~b}$ were found to have strong codon bias, similar to the bias found in other IBV genes, suggesting they had coding function. Second, no subgenomic mRNA with $\mathrm{lb}$ as its $5^{\prime}$-proximal ORF had been detected in IBVinfected cells. Third, nucleotide sequence comparisons of the la/lb overlap region with the gag-pol overlap region of Rous sarcoma virus (RSV) revealed a short but significant homology ( 8 out of 9 bases conserved) in the region where frameshifting was suspected to occur in RSV (Jacks and Varmus, 1985).

In order to test the possibility of ribosomal frameshifting in IBV, a region of cDNA corresponding to the $1 \mathrm{a} / 1 \mathrm{~b}$ overlap region was cloned within a reporter 
gene and tested for frameshifting by in vitro transcription and translation (Brierley et al., 1987). It was confirmed that the $1 \mathrm{a} / \mathrm{lb}$ region indeed specified a highly efficient -1 frameshift, with one in three ribosomes changing frame within the overlap region. This was the first nonretroviral example of the phenomenon. The IBV frameshift signal was also functional in vivo; synthetic transcripts containing the appropriate signals when injected into Xenopus oocytes produced the expected ratio of nonframeshifted to frameshifted products (Brierley et al., 1990).

In further experiments, the signals for frameshifting were investigated using site-directed mutagenesis (Brierley et al., 1991, 1992). These signals were shown to be located within an 86-nucleotide stretch encompassing the $1 \mathrm{a} / \mathrm{lb}$ overlap and were comprised of two main elements (see Fig. 2). The first was the sequence UUUAAAC, which was shown to be the actual site of the frame change; of the ribosomes that enter in the la frame (U-UUA-AAC), some $30 \%$ leave in the $1 \mathrm{~b}$ frame (UUU-AAA). This "slippery sequence" in itself was insufficient to evoke the change of frame, and additional information downstream is required. This information is in the form of an RNA pseudoknot, an unusual kind of RNA structure composed of two base-paired regions stacked coaxially in a quasi-continuous manner and connected by two single-stranded loop regions (Pleij and Bosch, 1989). The results indicated that no primary nucleotide sequence elements in the pseudoknot were required for the frameshift process; as long as the overall shape and predicted stability of the structure was maintained, frameshifting was highly efficient.

Frameshifting is thought to occur by simultaneous slippage into the -1 reading frame of two ribosome-bound tRNAs present in the aminoacyl and peptidyl sites of the ribosome during decoding of the slippery sequence. The role of the pseudoknot in this process is uncertain; the most plausible explanation advanced so far is that the presence of the pseudoknot may slow or stall the ribosome as it translates the slippery sequence, allowing realignment of the decoding tRNAs on the mRNA in a new frame (Jacks et al., 1988). Consistent with this idea is that the RNA pseudoknot must be within 5 to 7 nucleotides of the slip site for efficient frameshifting to occur in the IBV signal (Brierley et al., 1992), and additionally, that pausing at RNA pseudoknots can be demonstrated in vitro (Somogyi et al., 1993; Tu et al., 1992).

It is clear from recent work that the frameshift expression strategy appears to be conserved among coronaviruses (see Fig. 2). Frameshift signals have been described for MHV strains A59 (Bredenbeek et al., 1990b) and JHM (Lee et al., 1991) and also for HCV strain 229E (Herold et al., 1993; Herold and Siddell, 1993). In each case, the slippery sequence UUUAAAC is used and is followed by an RNA pseudoknot. For IBV and MHV, the pseudoknots are similar in terms of the size of the stems and the loop lengths, although the stem 2 of MHV is predicted to be longer. The pseudoknot of HCV 229E, however, forms a more complex structure. Loop 2 of the HCV pseudoknot is 164 nucleotides in length, by far the longest loop 2 seen in those pseudoknots involved in frameshifting. Furthermore, the nucleotides that form the second arm of stem 2 of the pseudoknot are themselves part of a hairpin loop that is predicted to form at the end of loop 2 (Herold and Siddell, 1993). This generates an additional stem, stem 3. It is 
IBV Beaudette

$100 p 2$

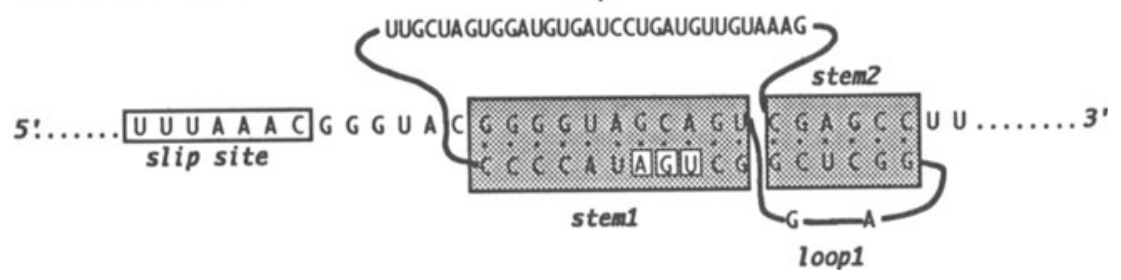

MHV A59

$100 p 2$

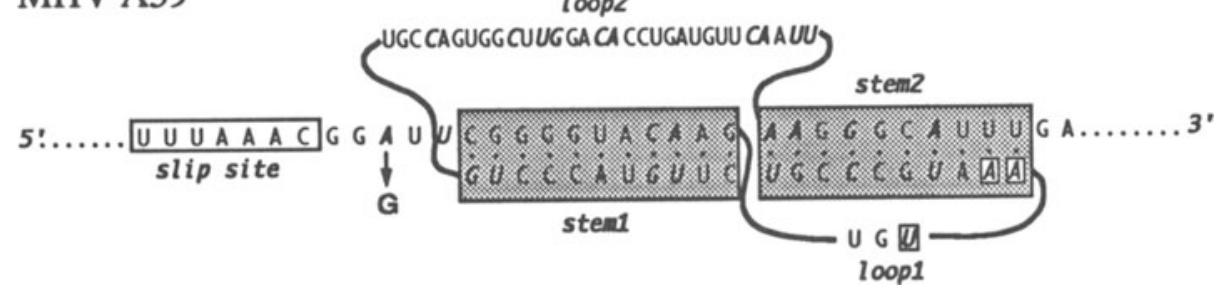

HCV 229E

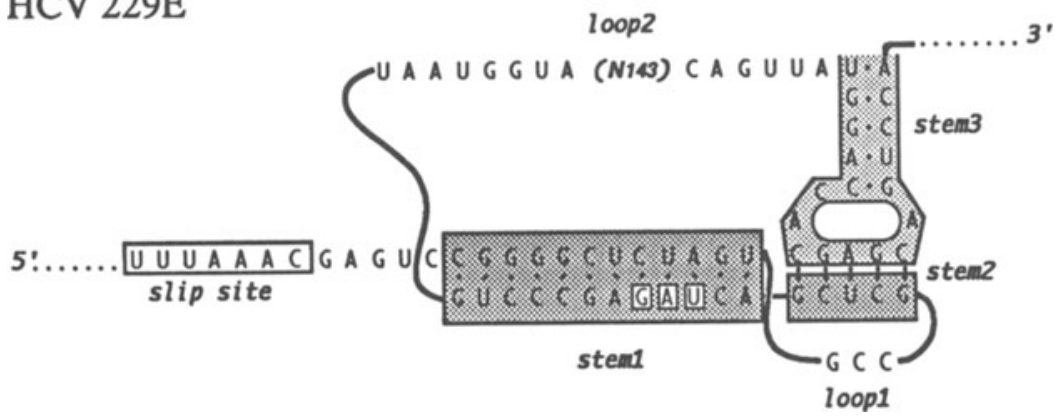

FIGURE 2. RNA pseudoknot structure associated with coronavirus frameshift sites. The italicized bases in the MHV A59 sequence are those that differ from those in the homologous IBV sequence (Boursnell et al., 1987; Bredenbeek et al., 1990). The frameshift signal of MHV JHM is identical to that of MHV A59 with exception of the indicated A to G change (Bredenbeek et al., 1990; Lee et al., 1991). In the case of each frameshift signal, the la termination codon is indicated by white, individually boxed characters. The data for HCV $229 \mathrm{E}$ are from Herold et al. (1993).

possible that the formation of this hairpin allows stem 2 to form more readily, compensating both for the extra length of loop 2 and the relative instability of the HCV stem 2, which has only five base pairs instead of the six base pairs seen for the other coronaviruses.

The discovery of the pseudoknot at the IBV frameshift site prompted a reevaluation of the components of retrovirus frameshift signals. It became clear that many retroviral frameshift sites also had the potential to form RNA pseudoknots (Brierley et al., 1989; ten Damm et al., 1990). Over the past few years, several of these signals have been investigated and the frameshift efficiency of the sites measured in vitro. It seems that the coronaviruses have the most efficient frameshift signals, with $30-40 \%$ of ribosomes changing frame. For retroviruses, the efficiency varies from a few percent up to $20 \%$. Clearly, the 
combination of the UUUAAAC sequence and a long, stable RNA pseudoknot in coronaviruses provides a very efficient frameshift signal. Why coronaviruses employ a frameshift strategy remains to be determined, but there are a number of possibilities. The most obvious is the likely requirement for production of a defined ratio of $1 \mathrm{a}: 1 \mathrm{a} / \mathrm{lb}$ products. In retroviruses, frameshifting generates the gag-pro, gag-pol, or gag-pro-pol polyproteins from which essential replication enzymes are derived. Disruption of the stoichiometry of the gag:gag-pol ratio is likely to have drastic consequences. The effect of modulation of the frameshift efficiency on virus viability has been studied for a double-stranded RNA virus, L-A, of Saccharomyces cerevisae, which employs a frameshift strategy to produce a gag-pol fusion protein. Experiments in which the ratio of gag:gagpol proteins in cells was varied have indicated that virus viability would be greatly reduced if the ratio is even moderately distorted (Dinman and Wickner, 1992).

Frameshifting may also be a strategy to avoid packaging defective RNAs. In retroviruses, the packaging signal is located $3^{\prime}$-ward of the splice donor such that only unspliced RNAs are packaged. If the gag-pol fusion protein were produced from an RNA in which the gag termination codon was removed by a small splicing event, then this RNA would be packaged and would be nonviable (since it would not be able to produce the gag and pol products in the correct stoichiometric amounts). Retroviruses avoid this problem by employing a frameshift strategy. The discovery that the MHV lb ORF contains the genomic packaging signal (van der Most et al., 1991) provides a possible explanation for the absence of a subgenomic mRNA for $1 b$, since this RNA would compete with the full-length genome for packaging into virions. Coronaviruses may well produce $1 \mathrm{~b}$ by frameshifting in order to avoid this predicament.

\section{Detection of the Products of mRNA 1 in Vivo}

Only limited success has been achieved in directly detecting coronavirus polymerase components in vivo. A single report has been presented in which a component was detected following radiolabeling of infected cells (Denison and Perlman, 1987). The $\mathrm{p} 28$ product, first detected in in vitro translation experiments with genomic RNA, was found in infected BALB/c 17CL-1 cells, but not in purified virions using two-dimensional gel electrophoresis. This small basic protein accumulated in the cells at late time.

More recently, monospecific antisera raised against synthetic peptides or bacterial fusion proteins containing coronavirus polymerase sequences have been used to detect polymerase components in infected cells. Products from both the IBV and MHV mRNA 1 ORFs have been detected using Western blotting (Brierley et al., 1990; Denison et al., 1991; Zoltick et al., 1990). A series of specific bands was observed, but it has not been possible to study their precursor-product relationships using this approach. Denison et al. (1991) used immunoprecipitation of radiolabeled MHV-A59-infected cell lysates with antipeptide or antifusion protein antisera to study the processing of the aminoterminus of the la polyprotein. The rapid appearance of $\mathrm{p} 28$ was demonstrated, but a complex spectrum of extremely high-molecular-weight products was de- 
tected by antisera directed against sequences downstream of the p28 coding region. Pulse-chase experiments suggested that polypeptides with apparent molecular weights of 240 and $50 \mathrm{kDa}$ might represent mature cleavage products from the polyprotein region encoded within the 5 -most $10 \mathrm{~kb}$ of MHV la.

More success has been achieved in detecting and characterizing discrete products from the IBV ORF $1 \mathrm{~b}$. A $100-\mathrm{kDa}$ polypeptide has been detected in infected cells by immunoprecipitation using an antibody raised against a region of the $1 \mathrm{~b}$ ORF containing the SDD polymerase motif. Mapping and processing mechanisms have been studied using $\mathrm{T} 7$ vaccinia/transfection approaches. The approximate position of the carboxy-terminus has been mapped using deletion analysis and is consistent with generation of the $100-\mathrm{kDa}$ polypeptide by cleavage at a Q/S site thought to be a target for the viral 3CLP (Gorbalenya et al., 1989). The position of the upstream cleavage site has not been determined experimentally, but the size of the processed product is consistent with a further 3CLP-mediated $\mathrm{Q} / \mathrm{S}$ cleavage. The role of the 3CLP in processing has been confirmed by deletion of the 3CLP domain from constructs containing la/lb sequences; this resulted in appearance of a full-length translation product and disappearance of the processed 100-kDa product (Liu et al., 1994).

The detection of RNA-dependent RNA polymerase activities in TGEV- and MHV-infected cells has been reported (Brayton et al., 1982, 1984; Dennis and Brian, 1982; Mahy et al.,1983) There is no direct evidence linking these activities to the expression of the unique region of mRNA 1 , but it is highly likely that they are a reflection of complexes formed between the range of polypeptides generated by processing of the $1 \mathrm{a}$ and lab polyproteins. The activity is associated with membranes and evidence has been presented for several distinct activities; an early activity involved in synthesizing full-length negative strands and a late activity which can be further subdivided into a replication fraction synthesizing full-length positive strands and a transcription fraction involved in production of both full-length and subgenomic mRNAs have been identified (Brayton et al., 1984).

\section{PUTATIVE NONSTRUCTURAL ORFs PRESENT IN THE SUBGENOMIC RNAs OF MHV}

\section{A. mRNA 2}

\section{The $2 \mathrm{a}$ ORF}

The MHV strains JHM and A59 differ in the expression of ORFs present in the genome between the polymerase and the spike genes. In the case of MHVJHM two mRNAs 2 and 2-1 have been identified; RNA 2 contains the $2 a$ ORF in its unique region, while RNA 2-1 contains the HE-encoding $2 b$ ORF in its unique region. MHV A59, on the other hand, appears to produce only a single mRNA 2 that contains the $2 a$ ORF and a defective $2 b$ ORF in its unique region. The $2 \mathrm{a}$ ORF is considered to encode a nonstructural polypeptide. The 2a ORF sequences are highly related in both MHV-JHM and A59 (Luytjes et al., 1988; Shieh et al., 1989), potentially coding for, respectively, a 265 and a 261 amino 
acid polypeptide. Computer analysis of the ORF has suggested the possible presence of a nucleotide binding site with the possible implication of a nucleic acid binding function (Luytjes et al., 1988). No homologue of the 2a ORF is found in IBV, TGEV, FIPV, or CCV.

\section{The 2a Product}

A 30- to 35-kDa product expressed from purified MHV RNA 2 was detected following in vitro translation of purified RNA (Leibowitz et al., 1982; Siddell, 1983). Products of this size had previously been identified in MHV-infected cells (Bond et al., 1979; Siddell et al., 1981). The expression of the 2a product in MHVinfected cells has been confirmed using antisera raised against bacterial fusion proteins containing parts of the putative 2 a sequence (Bredenbeek et al., 1990a; Zoltick et al., 1990). A 30-kDa product was identified by both groups. It had a cytosolic localization (Zoltick et al., 1990). The pattern of its expression was similar to that of virus structural proteins, but it had a more rapid turnover than the nucleocapsid protein. It was not detected in purified virions (Bredenbeek et al., 1990a). The function of the $30-\mathrm{kDa}$ product remains unknown, but it has been shown that strains of MHV-JHM deleted for 2a show normal growth properties in vitro. It is therefore possible that the 2 a gene product is only of significance when the virus is growing in vivo (Schwarz et al., 1990).

\section{B. mRNA 4}

\section{The 4 ORF}

The unique region of mRNA 4 contains an ORF potentially capable of translation to produce a 139-residue polypeptide (Skinner and Siddell, 1985). Analysis of the predicted amino acid sequence revealed a number of interesting features. It has a large hydrophobic amino-terminus and a basic carboxyterminus. It has a strikingly high content of threonine residues outside the hydrophobic region.

\section{The 4 Product}

Early in vitro translation studies failed to conclusively assign a polypeptide product of mRNA 4. A product of the size predicted to result from the translation of the RNA has been detected in infected cells (Siddell et al., 1981) and in in vitro translation products of RNA fractions enriched for mRNAs 4 and 5 (Siddell, 1983). The similarity in size of the mRNA 4 ORF and ORFs found in the unique region of mRNA 5 made a coding assignment unsatisfactory on the basis of these data. The difficulty was resolved by the production of a specific antiserum against a bacterial fusion protein consisting of $\beta$-galactosidase fused to the predicted carboxy-terminus of the mRNA 4 polypeptide (Ebner et al., 1988). The use of this antiserum in immunoprecipitation studies confirmed the expression of the predicted polypeptide in infected cells that was detected as a 15$\mathrm{kDa}$ product. Its correlation with the previously observed in vitro translation 
product of approximately $15 \mathrm{kDa}$ was also confirmed by immunoprecipitation. Immunofluorescence studies demonstrated a cytoplasmic location. The possibility that it was as major virion component was excluded; the antiserum possessed no neutralizing activity. The function of the $15-\mathrm{kDa}$ product remains unknown. The mutation of the gene 4 transcriptional initiation signal in the MHV S strain, which prevents synthesis of the gene 4 mRNA, has no effect on growth in DBT cells (Yokomori and Lai, 1991).

\section{C. mRNA 5}

Sequencing of the unique region of mRNA 5 of MHV-JHM and MHV-A59 revealed the presence of two ORFs, 5a and b (Budzilowicz and Weiss, 1987; Skinner et al., 1985). No mRNA that might allow expression of the downstream ORF by a conventional scanning mechanism has been observed; no transcriptional signals were obvious in the sequence immediately upstream of the 5b ORF.

\section{The 5a ORF}

This is 321 bases in length in MHV-JHM and 336 bases in length in MHVA59; it potentially encodes polypeptides of molecular weights $12.4 \mathrm{kDa}$ (107 residues) and $13 \mathrm{kDa}$ (112 residues), respectively. The predicted polypeptide is basic.

\section{The 5a Product}

The putative product of the 5a ORF has only been detected by in vitro translation of synthetic mRNA (Budzilowicz and Weiss, 1987). Deletion of almost the whole of the 5a ORF in the MHV S strain has no effect on its growth in DBT cells (Yokomori and Lai, 1991).

\section{The $5 \mathrm{~b}$ ORF}

This is 264 bases in length in MHV-JHM and 249 bases in length in MHVA59; it potentially encodes polypeptides of molecular weights $10.2 \mathrm{kDa} / 88$ residues) and $9.6 \mathrm{kDa}$ ( 83 residues), respectively. The predicted polypeptide has a strongly hydrophobic region toward the amino-terminus.

\section{The 5b Product}

Recently, it has been shown that the ORF 5b product is, in fact, the sM polypeptide of MHV (Yu et al., 1994). Previously, a 9- to 10-kDa product was detected in MHV-infected cells by Skinner et al. (1985) and was proposed as a candidate for the product of the $5 \mathrm{~b}$ ORF. Its synthesis in in vitro translation reactions was correlated to the abundance of mRNA 5 in the RNA preparations. The potential for expression of this ORF was confirmed by in vitro translation 
of synthetic mRNAs produced by $\mathrm{T} 7$ polymerase transcription of cloned cDNA sequences (Budzilowicz and Weiss, 1987). It is interesting to note that expression of the downstream $5 \mathrm{~b}$ ORF from RNAs containing both ORFs was substantially more efficient than that of the upstream 5a ORF. However, the RNA species analyzed did not have the structure of the natural mRNA 5. The mechanism of the selectivity was not clarified.

The finding of a suboptimal initiator AUG context for the 5a ORF and the absence of internal methionine residues in its predicted sequence coupled with codon usage data had suggested that both ORFs might be expressed, possibly by a leaky scanning mechanism, but recent work using synthetic mRNAs has demonstrated that the translation of $5 \mathrm{~b}$ is likely to involve internal entry of ribosomes (Thiel and Siddell, 1994). The expression of the 5b ORF in infected cells has been demonstrated using a specific antiserum raised against a $\mathrm{recA} / 5 \mathrm{~b} / \beta$-galactosidase fusion protein expressed in $E$. coli (Leibowitz et al., 1988). The antiserum detected the $5 \mathrm{~b}$ product in infected cells using both peroxidase labeling of fixed cells and immunoprecipitation of infected cell extracts. The observed size was consistent with that of the 9- to 10-kDa product previously detected in infected cells by Skinner et al. (1985).

\section{PUTATIVE NONSTRUCTURAL POLYPEPTIDE ORFs PRESENT IN THE SUBGENOMIC RNAs OF BCV}

\section{A. mRNA 2-1}

The close sequence relationship of $\mathrm{BCV}$ to $\mathrm{MHV}$ is reflected in part by the pattern of subgenomic RNAs detected in BCV infected cells. mRNA 2 has a unique region potentially coding for a nonstructural polypeptide and a mRNA 2-1 coding for the HE protein as in MHV-JHM (Keck et al., 1988).

\section{The $2 \mathrm{a}$ ORF}

The sequence of the single ORF present in the unique region of mRNA 2 has been determined (Cox et al., 1989). The predicted polypeptide has a size of $32 \mathrm{kDa}$. It shares nucleotide $(65 \%)$ and amino acid $(45 \%)$ homology with the predicted product of the MHV 2a ORF. An antiserum raised against a $\beta$-galactosidase fusion protein has been used to detect expression of the 2a polypeptide (ns2) in infected cells. It has been demonstrated to be a nonstructural phosphoprotein that accumulates in the cytoplasm during infection. The phosphorylation occurs on serine and threonine residues (Cox et al., 1991).

\section{B. mRNA 4}

The unique region of mRNA 4 as defined by consensus intergenic homology regions contains two small ORFs (Abraham et al., 1990). An RNA species likely to correspond to this unique region has been detected (Keck et al., 1988). 
The MHV RNA 4 codes for a single larger polypeptide; the possibility of an artifactual origin for the two BCV ORFs has been eliminated by sequencing of independently cloned cDNAs. It is suggested that the two ORFs have arisen as a result of a one-base deletion in the middle of a single ancestral ORF (Abraham et al., 1990). The addition of a single base gives a single ORF of $11 \mathrm{kDa}$ with substantial homology to the 15-kDa product of MHV ORF 4.

\section{The $4 \mathrm{a}$ ORF}

This predicts a polypeptide of $4.9 \mathrm{kDa}$.

\section{The $4 \mathrm{~b}$ ORF}

This predicts a polypeptide of $4.8 \mathrm{kDa}$.

\section{C. mRNAs 5 and 5-1}

Initial analyses of the subgenomic RNAs found in BCV-infected cells suggested a single mRNA between mRNA 4 and mRNA 6 (Keck et al., 1988). Sequence analysis of the putative unique region of this RNA suggested that an additional consensus signal for transcriptional initiation is present in this region and a reexamination of the subgenomic RNAs corresponding to the region revealed the presence of an additional species, 5-1 (Abraham et al., 1990). Thus, again, there is a contrast with the situation found in the related virus MHV where a single RNA species contains both the 5a and 5b ORFs in its unique region and the downstream ORF appears to be efficiently expressed (Budzilowicz and Weiss, 1987; Leibowitz et al., 1988; Skinner et al., 1985). The likely role of the 5-1 RNA in the expression of the homologue of MHV $5 \mathrm{~b}$ is suggested by the observation that translation of in vitro transcripts containing both the 5 and 5-1 ORFs does not result in efficient synthesis of the downstream 5-1 product (Abraham et al., 1990). It is, however, efficiently synthesized when in the upstream position.

\section{The 5 ORF}

This predicts a 109 -amino acid, $12.7-\mathrm{kDa}$ polypeptide. It has approximately $50 \%$ amino acid homology with the 12.4- and 13-kDa polypeptides of MHVJHM and MHV-A59, respectively (Budzilowicz and Weiss, 1987; Skinner et al., 1985).

\section{The 5-1 ORF}

This predicts an 84 -amino acid, 9.5 -kDa polypeptide. This has greater than $60 \%$ amino acid homology with the 10.2 - and $9.6-\mathrm{kDa}$ polypeptides of MHVJHM and MHV-A59, respectively (Budzilowicz and Weiss, 1987; Skinner et al., 1985). 


\section{The 5-1 Product}

The synthesis of this product in infected cells has been demonstrated using immunofluorescence. The specific antiserum used was that prepared against the MHV 5b product (Leibowitz et al., 1988). It is expressed both internally and on the surface of infected cells. This would be consistent with the presence of a potentially membrane-spanning hydrophobic region. As in the case of MHV, the $5 \mathrm{~b}$ polypeptide may, in fact, be the sM polypeptide of BCV (Godet et al., 1992).

\section{PUTATIVE NONSTRUCTURAL POLYPEPTIDE ORFs PRESENT IN THE SUBGENOMIC RNAs OF HCV-OC43}

HCV-OC43 and BCV show remarkable similarity in terms of nucleotide sequence and immunological cross-reactivity of their structural proteins, implying a close "evolutionary" relationship. The region between the S and M proteins predicted on the basis of this relationship to encode nonstructural proteins has been cloned and sequenced (Mounir and Talbot, 1993). As expected it contains ORFs with high homology to those encoding nonstructural polypeptides in the corresponding region of $\mathrm{BCV}$, but only two ORFs were identified. They appear to be expressed from separate mRNAs (5 and 5-1) as are their counterparts in BCV. The ORFs expected to be expressed from mRNA 4 are absent, but, surprisingly, the mRNA is still expressed.

\section{A. The 5 ORF}

This predicts a 109 amino acid $12.7-\mathrm{kDa}$ polypeptide. It has $96.3 \%$ amino acid identity with its BCV homologue.

\section{B. The 5-1 ORF}

This predicts an 84 -amino acid, 9.5-kDa polypeptide. This has $96.4 \%$ identity with its BCV counterpart. This may be the sM polypeptide of HCV OC43.

\section{PUTATIVE NONSTRUCTURAL POLYPEPTIDE ORFS PRESENT IN THE SUBGENOMIC RNAs OF TGEV AND PRCV}

Two large ORFs encoding putative nonstructural polypeptides have consistently been identified between the spike and small membrane genes of TGEV, but there have been differing reports of size and putative mechanisms of expression (Britton et al., 1989; Kapke et al., 1989; Rasschaert et al., 1987; Wesley et al., 1989). It is possible that in some strains of virus they are expressed from two mRNAs, whereas in others only one involved. In one case the existence of the 
two RNA species has been demonstrated by Sl mapping (Wesley et al., 1989). However, for simplicity, the ORFs and their products will be described within both frameworks; the putative mRNAs will be referred to as $3(3-1)$ and the ORFs as $3(3 a)$ and 3-1 (3b). An extreme 3' ORF and corresponding mRNA (7) has been also been identified (Britton et al., 1989; de Groot et al., 1988; Jacobs et al., 1986).

\section{A. mRNA 3}

\section{The $3(3 a)$ ORF}

Two groups have sequenced the region containing this ORF using cDNA clones derived from the tissue culture-adapted Purdue strain of TGEV (Kapke et al., 1989; Rasschaert et al., 1987). The predicted polypeptides are identical, being $7.7 \mathrm{kDa}$ in size. Two further sequences from virulent isolates, the FS772/70 strain (Britton et al., 1989) and the Miller strain (Wesley et al., 1989) have been determined. The predicted polypeptides differ in these cases, being $6.6 \mathrm{kDa}$ and $7.9 \mathrm{kDa}$, respectively, in size. All groups have identified a putative upstream transcription reinitiation site thought to be involved in synthesis of mRNA 3. Its function has been confirmed using S1 mapping in one case (Wesley et al., 1989|. The sequences of these predicted polypeptides have been analyzed using various computer-based techniques, but no characteristics suggestive of function have been identified.

The putative initiation site for transcription mRNA 3 and part of the $3 a$ ORF is missing from the porcine respiratory coronavirus (PRCV) sequence. It is unlikely, therefore, that the 3a ORF is expressed in this "variant" of TGEV (Page et al., 1991).

\section{The 3-1 (3b) ORF}

The region containing this ORF has again been sequenced by four groups using the Purdue strain and the two virulent strains, FS772/70 and Miller (Britton et al., 1989; Kapke et al., 1989; Rasschaert et al., 1987; Wesley et al., 1989). A striking discrepancy between the two Purdue sequences has been noted. The sequence of Rasschaert et al. (1987) predicted a polypeptide of 18.8 $\mathrm{kDa}$; the subsequent work of Kapke et al. (1988) suggested that there may have been a sequencing error in the initial study leading to a truncation of the predicted 3-1 ORF. The data of Kapke et al. (1988) are consistent with the observation of a $24-\mathrm{kDa}$ in vitro translation product from mRNA 3-enriched preparations (Jacobs et al., 1986) and the subsequent virulent strain ORF size predictions of $27.6 \mathrm{kDa}$ (FS772/70) (Britton et al., 1989) and $27.7 \mathrm{kDa}$ (Miller) (Wesley et al., 1989). The most notable feature of this predicted ORF is the hydrophobicity of its $\mathrm{N}$-terminus and the clustering of charged residues at the carboxy-terminus.

In PRCV, the 3 (3b) ORF is likely to expressed from a $5^{\prime}$ truncated version of mRNA 3 transcribed from a novel initiation site immediately upstream of ORF 3 (Page et al., 1991). 


\section{B. mRNA 7}

\section{The 7 ORF}

The sequencing of the extreme $3^{\prime}$ end of the TGEV genome has revealed the presence of a small ORF that may be expressed from a 0.7-kb mRNA (Britton et al., 1989; Kapke and Brian, 1986; Rasschaert et al., 1987). The 9-kDa polypeptide predicted by the ORF has the characteristics of a membrane polypeptide; it contains hydrophobic sequences at the $\mathrm{N}$ - and $\mathrm{C}$-termini separated by a central hydrophilic region.

\section{PUTATIVE NONSTRUCTURAL POLYPEPTIDE ORFs PRESENT IN THE SUBGENOMIC RNAS OF FIPV AND FECV}

Two mRNAs (other than the genomic RNA, RNA 1) that may encode nonstructural polypeptides have been identified in FIPV-infected cells; these are a 5.2-kb (RNA 3) and a 1.6-kb (RNA 6) species (de Groot et al., 1987). Sequence data are only available for the unique region of RNA 6 (de Groot et al., 1988).

\section{A. mRNA 6}

\section{The 6a ORF}

In the genomic sequence, this ORF overlaps with the $3^{\prime}$ end of the nucleocapsid ORF. S1 nuclease analysis, however, has demonstrated that only sequences downstream of the nucleocapsid ORF are contained in mRNA 6 (de Groot et al., 1988). This is consistent with the finding of a consensus transcription initiation signal at the mRNA body junction detected by S1 mapping. On this basis the 6a ORF predicts an 11-kDa polypeptide. The 11-kDa polypeptide predicted by ORF 6a of FIPV is strongly homologous to the $9-\mathrm{kDa}$ polypeptide predicted by the 7 ORF of TGEV. ORF 6a of FIPV is 69 nucleotides longer than ORF 7 of TGEV. The insertion extends the hydrophilic central part of the predicted polypeptide. The feline enteric coronavirus (FECV) 6a polypeptide is $99 \%$ identical (one amino acid difference) with that of FIPV (Vennema et al., 1992).

\section{The $6 \mathrm{~b}$ ORF}

This ORF predicts a $22-\mathrm{kDa}$ polypeptide that is not homologous to any TGEV polypeptide. It is hydrophilic with a short hydrophobic section at the $\mathrm{N}$-terminus. There is no consensus transcription initiation signal appropriate for expression of this ORF from its own mRNA and no RNA smaller than the $1.6-\mathrm{kb}$ species containing both $6 \mathrm{a}$ and $6 \mathrm{~b}$ has been detected in infected cells /de Groot et al., 1988) The putative methionine initiation codon for the 6b ORF is in an optimal context. The 6a ORF contains two internal methionine residues in 
addition to the initiator methionine, but these are in poor contexts. This situation, however, does contrast with that found in other cases where leaky scanning expression of downstream coronavirus ORFs has been invoked; in these cases, internal methionines are absent from the upstream ORFs (Boursnell et al., 1985; Skinner et al., 1985). The FECV 6b ORF shows a carboxy-terminal deletion when compared to that of FIPV; the amino-terminal 123 residues show $89 \%$ identity to the equivalent FIPV sequence (Vennema et al., 1992).

\section{PUTATIVE NONSTRUCTURAL POLYPEPTIDE ORFS PRESENT IN THE SUBGENOMIC RNAS OF CCV}

Of a CCV sequence, $9.6 \mathrm{~kb}$ extending from the region encoding the carboxyterminus of ORF $1 \mathrm{~b}$ to the $3^{\prime}$ end of the genome is available for strain Insavc-1 (Horsburgh et al., 1992). Sequences from the extreme 3' end of the genomes of strains K378 and I-71 are also available (Vennema et al., 1992). Two mRNAs (3 and 7) each encoding two putative nonstructural polypeptides have been identified.

\section{A. mRNA 3}

1. The 3a ORF

This encodes a $8.6-\mathrm{kDa}$ polypeptide that shows $83.5 \%$ identity to the TGEV 3a polypeptide (Horsburgh et al., 1992).

\section{The $3 \mathrm{~b}$ ORF}

This encodes a 4.0-kDa polypeptide. This modest coding potential is the consequence of a termination codon present within a "potentially larger" ORF $(28.4 \mathrm{kDa})$ that has $92.4 \%$ identity with the equivalent TGEV ORF (Horsburgh et al., 1992). In spite of the presence of a potential transcriptional initiator sequence immediately upstream of the $3 \mathrm{~b}$ ORF, no evidence for the synthesis of a corresponding mRNA has been obtained (Horsburgh et al., 1992).

\section{PUTATIVE NONSTRUCTURAL POLYPEPTIDE ORFS PRESENT IN THE SUBGENOMIC RNAs OF HCV 229E}

The unique regions of mRNA 4 and 5 of HVC 229E have been sequenced (Jouvenne et al.,1992; Raabe et al., 1990; Raabe and Siddell, 1989).

\section{A. mRNA 4}

\section{The 4a ORF}

This ORF predicts a polypeptide of $15.3 \mathrm{kDa}$ that lacks internal methionines (Raabe et al., 1990; Raabe and Siddell, 1989). 


\section{The $4 \mathrm{~b}$ ORF}

This ORF predicts a polypeptide of $10.2 \mathrm{kDa}$ that is characterized by a hydrophobic amino-terminus (Raabe et al., 1990; Raabe and Siddell, 1989). cDNAs encoding deleted versions of ORFs $4 \mathrm{a}$ and $4 \mathrm{~b}$ have been cloned and sequenced; the predicted polypeptide products are $4.7 \mathrm{kDa}$ and $9.6 \mathrm{kDa}$, respectively. It seems likely that the cDNAs were derived from a minor mRNA species (Jouvenne et al., 1992).

\section{B. mRNA 5}

\section{The 5 ORF}

This ORF predicts a hydrophobic polypeptide of $9.1 \mathrm{kDa}$ that is homologous to the corresponding sM polypeptide of TGEV (Godet et al., 1992).

\section{PUTATIVE NONSTRUCTURAL POLYPEPTIDE ORFs PRESENT IN THE SUBGENOMIC RNAs OF IBV}

\section{A. mRNA 3}

Nucleotide sequences for the unique region region of IBV mRNA 3 have been reported for three virus strains: Beaudette, M41, and KB8523 (Boursnell et al., 1985; Niesters et al., 1986; Sutou et al., 1988). The predicted amino sequences of the three ORFs detected are conserved in all strains. The absence of internal methionines and the poor contexts of the initiator methionines of the upstream ORFs initially focused attention on the possibility of downstream ORF expression by leaky scanning, but it has been subsequently demonstrated that expression of the 3c ORF involves internal ribosome entry (Liu and Inglis, 1992). There is no evidence for individual mRNAs for the three ORFs.

\section{The 3a ORF}

The polypeptide predicted to be translated from this ORF has a molecular weight of $6.7 \mathrm{kDa}$. It is neutral and hydrophobic. It has been detected in infected cells using antifusion protein antisera (Liu et al., 1991).

\section{The $3 \mathrm{~b}$ ORF}

The polypeptide predicted by this ORF has a molecular weight of $7.4 \mathrm{kDa}$. It is highly acidic. It has been detected in infected cells using antifusion protein antisera (Liu et al., 1991).

\section{The 3c ORF}

The polypeptide predicted by this ORF has molecular weight of $12.4 \mathrm{kDa}$. It has a hydrophobic domain near the $\mathrm{N}$-terminus, potentially capable of spanning 
cellular membranes, and a hydrophilic C-terminal domain. The hydrophobic domain is flanked by hydrophilic residues. Codon usage in the 12.4-kDa ORF conforms to that of the IBV structural proteins; the codon usage of the 6.7-and 7.4-kDa ORFs does not.

\section{The 3c Product}

The expression of the $3 \mathrm{c}$ polypeptide product in IBV-infected cells has been demonstrated using a specific antiserum raised against a bacterial fusion protein consisting of $\beta$-galactosidase and the complete $3 c$ coding region $(\mathrm{Smith}$ et al., 1990). A 12.4-kDa product was detected in infected cells by immunoprecipitation. It was largely located in the large-membrane subcellular fraction of infected cells along with the spike and membrane glycoproteins; nucleocapsid was, on the other hand, found largely in the microsomal fraction. This is consistent with a membrane location for the $3 \mathrm{c}$ product. Immunofluorescence studies demonstrated that the polypeptide was located internally and on the cell surface; there was some indication of the internal fraction of $3 \mathrm{c}$ being located in the Golgi and that the $3 \mathrm{c}$ polypeptide is present in virions (Liu and Inglis, 1991). It is clear that it is homologous to the sM polypeptide of TGEV.

\section{B. mRNA 5}

The nucleotide sequence of the unique region of IBV mRNA 5 has been determined for the Beaudette strain (Boursnell and Brown, 1984). Two ORFs were identified. No evidence for an mRNA capable of expressing the downstream ORF independently has been obtained. Neither predicted polypeptide contains an internal methionine.

\section{The 5a ORF}

The predicted polypeptide has a molecular weight of $7.5 \mathrm{kDa}$. The polypeptide is hydrophobic, having a very high leucine content (17 of 65 residues).

\section{The $5 \mathrm{~b}$ ORF}

The predicted polypeptide has a molecular weight of $9.5 \mathrm{kDa}$.

\section{CONCLUSION}

All coronaviruses appear to encode a substantial number of nonstructural polypeptides; this is consistent with their genetic complexity. The ORFs present in the unique regions of the genomic RNA (mRNA 1) from IBV, MHV, and HCV show substantial homology in amino acid sequence and in their organization. The smaller putative nonstructural ORFs are, however, more heterogeneous in predicted sequence, genomic location, and putative mode of expres- 
sion even within clusters of related viruses. This plasticity is particularly striking in the case of polypeptides encoded between $S$ and $M$. Expression in infected cells of many of the ORFs detected by sequencing has not yet been demonstrated and there is little or no insight into their functions. It will difficult to determine these functions in the absence of systems, for example, for genetic analysis of in vitro replication/transcription and for the production of site-directed mutations in the viral genome.

\section{REFERENCES}

Abraham, S., Kienzle, T. E., Lapps, W. E., and Brian, D. A., 1990, Sequence and expression analysis of potential nonstructural proteins of $4.9,4.8,12.7$, and $9.5 \mathrm{kDa}$ encoded between the spike and membrane protein genes of the bovine coronavirus, Virology 177:488.

Argos, P., 1988, A sequence motif present in many polymerases, Nucleic Acids Res. 16:9909.

Baker, S. C., Shieh, C. K., Soe, L. H., Chang, M. F., Vannier, D. M., and Lai, M. M., 1989, Identification of a domain required for autoproteolytic cleavage of murine coronavirus gene A polyprotein, J. Virol. 63:3693.

Baker, S. C., Yokomori, K., Dong, S., Carlisle, R., Gorbalenya, A. E., Koonin, E. V., and Lai, M. M., 1993, Identification of the catalytic sites of a papain-like cysteine proteinase of murine coronavirus, J. Virol. 67:6056.

Bond, C. W., Leibowitz, J. L., and Robb, J. A., 1979, Pathogenic murine coronaviruses. II. Characterisation of virus-specific proteins of murine coronaviruses JHMV and A59V, Virology 94:371.

Bonilla, P. J., Gorbalenya, A. E., and Weiss, S. R., 1994, Mouse hepatitis virus strain A59 polymerase gene ORF la: heterogeneity among MHV strains, Virology 198:736.

Boursnell, M. E. G., and Brown, T. D. K., 1984, Sequencing of coronavirus IBV genomic RNA: A 195base open reading frame encoded by mRNA B, Gene 29:87.

Boursnell, M. E., Binns, M. M., and Brown, T. D. K., 1985, Sequencing of coronavirus IBV genomic RNA: three open reading frames in the 5 " "unique" region of mRNA D, J. Gen. Virol. 66:2253.

Boursnell, M. E., Brown, T. D. K., Foulds, I. J., Green, P. F., Tomley, F. M., and Binns, M. M., 1987, Completion of the sequence of the genome of the coronavirus avian infectious bronchitis virus, J. Gen. Virol. 68:57.

Brayton, P. R., Lai, M. M. C., Patton, C. D., and Stohlman, S. A., 1982, Characterization of two RNA polymerase activities induced by mouse hepatitis virus, J. Virol. 42:847.

Brayton, P. R., Stohlman, S. A., and Lai, M. M. C., 1984, Further characterization of mouse hepatitis virus RNA-dependent RNA polymerases, Virology 133:197.

Bredenbeek, P. J., Noten, A. F. H., Horzinek, M. C., and Spaan, W. J. M., 1990a, Identification and stability of a 30-kDa non-structural protein encoded by mRNA 2 of mouse hepatitis virus in infected cells, Virology 175:303.

Bredenbeek, P. J., Pachuk, C. J., Noten, A. F., Charite, J., Luytjes, W., Weiss, S. R., and Spaan, W. J., $1990 \mathrm{~b}$, The primary structure and expression of the second open reading frame of the polymerase gene of the coronavirus MHV-A59; a highly conserved polymerase is expressed by an efficient ribosomal frameshifting mechanism, Nucleic Acids Res. 18:1825.

Brierley, I., Boursnell, M. E., Binns, M. M., Bilimoria, B., Blok, V. C., Brown, T. D. K., and Inglis, S. C., 1987, An efficient ribosomal frame-shifting signal in the polymerase-encoding region of the coronavirus IBV, EMBO T. 6:3779.

Brierley, I., Digard, P., and Inglis, S. C., 1989, Characterization of an efficient coronavirus ribosomal frameshifting signal: Requirement for an RNA pseudoknot, Cell 57:537.

Brierley, I., Boursnell, M. E., Binns, M. M., Bilimoria, B., Rolley, N. J., Brown, T. D. K., and Inglis, S. C., 1990, Products of the polymerase-encoding region of the coronavirus IBV, in: Coronaviruses and Their Diseases, Advances in Experimental Biology and Medicine, 276 (D. Cavanagh and T. D. K. Brown, eds.), p. 275, Plenum Press, New York.

Brierley, I., Jenner, A. J., and Inglis, S. C., 1992, Mutational analysis of the "slippery-sequence" component of a coronavirus ribosomal frameshifting signal, I. Mol. Biol. 227:463. 
Britton, P., Lopez Otin, C., Martin Alonso, J., and Parra, F., 1989, Sequence of the coding regions from the $3.0 \mathrm{~kb}$ and $3.9 \mathrm{~kb}$ mRNA. Subgenomic species from a virulent isolate of transmissible gastroenteritis virus, Arch. Virol. 105:165.

Budzilowicz, C. J., and Weiss, S. R., 1987, In vitro synthesis of two polypeptides from a nonstructural gene of coronavirus mouse hepatitis virus strain A59, Virology 157:509.

Cox, G. J., Parker, M. D., and Babiuk, L. A., 1989, The sequence of cDNA of bovine coronavirus 32K nonstructural gene, Nucleic Acids Res. 17:5847.

Cox, G. J., Parker, M. D., and Babiuk, L. A., 1991, Bovine coronavirus nonstructural protein ns2 is a phosphoprotein, Virology 185:509.

de Groot, R. J., ter-Haar, R. J., Horzinek, M. C., and van-der-Zeijst, B. A., 1987, Intracellular RNAs of the feline infectious peritonitis coronavirus strain 79-1146, J. Gen. Virol. 68:995.

de Groot, R. J., Andeweg, A. C., Horzinek, M. C., and Spaan, W. J., 1988, Sequence analysis of the 3 '-end of the feline coronavirus FIPV 79-1146 genome: Comparison with the genome of porcine coronavirus TGEV reveals large insertions, Virology 167:370.

Denison, M. R., and Perlman, S., 1986, Translation and processing of mouse hepatitis virus virion RNA in a cell-free system, J. Virol. 60:12.

Denison, M., and Perlman, S., 1987, Identification of putative polymerase gene product in cells infected with murine coronavirus A59, Virology 157:565.

Denison, M. R., Zoltick, P. W., Leibowitz, J. L., Pachuk, C. J., and Weiss, S. R., 1991, Identification of polypeptides encoded in open reading frame $\mathrm{lb}$ of the putative polymerase gene of the murine coronavirus mouse hepatitis virus A59, J. Virol. 65:3076.

Dennis, D. E., and Brian, D. A., 1982, RNA-dependent RNA polymerase activity in coronavirusinfected cells, J. Virol. 42:153.

Dinman, J. D., and Wickner, R. B., 1992, Ribosomal frameshifting efficiency and gag/gag-pol ratio are critical for yeast M1 double-stranded RNA virus propagation, $J$. Virol. 66:3369.

Ebner, D., Raabe, T., and Siddell, S. G., 1988, Identification of the coronavirus MHV-JHM mRNA 4 product, J. Gen. Virol. 69:1041.

Godet, M., l'Haridon, R., Vautherot, J. F., and Laude, H., 1992, TGEV corona virus ORF4 encodes a membrane protein that is incorporated into virions, Virology 188:666.

Gorbalenya, A. E., Koonin, E. V., Donchenko, A. P., and Blinov, V. M., 1988a, A conserved NTPmotif in putative helicases, Nature 333:22.

Gorbalenya, A. E., Koonin, E. V., Donchenko, A. P., and Blinov, V. M., 1988b, A novel superfamily of nucleoside triphosphate-binding motif containing proteins which are probably involved in duplex unwinding in DNA and RNA replication and recombination, FEBS Lett. 235:16.

Gorbalenya, A. E., Blinov, V. M., Donchenko, A. P., and Koonin, E. V., 1989a, An NTP-binding motif is the most conserved feature in a highly diverged monophyletic group of proteins involved in positive strand RNA viral replication, J. Mol. Evol. 28:256.

Gorbalenya, A. E., Koonin, E. V., Donchenko, A. P., and Blinov, V. M., 1989b, Coronavirus genome: Prediction of putative functional domains in the non-structural polyprotein by comparative amino acid sequence analysis, Nucleic Acids Res. 17:4847.

Gorbalenya, A. E., Koonin, E. V., and Lai, M. M., 1991, Putative papain-related thiol proteases of positive-strand RNA viruses. Identification of rubi- and aphthovirus proteases and delineation of a novel conserved domain associated with proteases of rubi-, alpha- and coronaviruses, FEBS Lett. 288:201.

Hardy, W. R., and Strauss, J. H., 1989, Processing the non-structural polyproteins of Sindbis virus: Non-structural proteinase is in the C-terminal half of $\mathrm{nsP} 2$ and functions both in cis and in trans, I. Virol. 63:4653.

Herold, J., and Siddell, S. G., 1993, An elaborated pseudoknot is required for high-frequency frameshifting during translation of HCV 229E polymerase messenger RNA, Nucleic Acids Res. 21:5838.

Herold, J., Raabe, T., Schelle-Prinz, B., and Siddell, S. G., 1993, Nucleotide sequence of the human coronavirus 229E RNA polymerase locus, Virology 195:680.

Hodgman, T. C., 1988, A new superfamily of replicative proteins, Nature 333:22.

Horsburgh, B. C., Brierley, I., and Brown, T. D., 1992, Analysis of a $9.6 \mathrm{~kb}$ sequence from the 3 ' end of canine coronavirus genomic RNA, J. Gen. Virol. 73:2849. 
Jacks, T., and Varmus, H. E., 1985, Expression of the Rous sarcoma virus pol gene by ribosomal frameshifting, Science 230:1237.

Jacks, T., Madhani, H. D., Masiarz, F. R., and Varmus, H. E., 1988, Signals for ribosomal frameshifting in the Rous sarcoma virus gag-pol region, Cell 55:447.

Jacobs, L., van der Zeijst, B. A. M., and Horzinek, M. C., 1986, Characterisation and translation of transmissible gastroenteritis virus mRNAs, J. Gen. Virol. 57:1010.

Jouvenne, P., Mounir, S., Stewart, J. N., Richardson, C. D., and Talbot, P. J., 1992, Sequence analysis of human coronavirus 229E mRNAs 4 and 5: Evidence for polymorphism and homology with myelin basic protein, Virus Res. 22:125.

Kapke, P. A., and Brian, D. A., 1986, Sequence analysis of the porcine transmissible gastroenteritis coronavirus nucleocapsid protein gene, Virology 151:41.

Kapke, P. A., Tung, F. Y., and Brian, D. A., 1989, Nucleotide sequence between the peplomer and matrix protein genes of the porcine transmissible gastroenteritis coronavirus identifies three large open reading frames, Virus Genes 2:293.

Keck, J. G., Hogue, B. G., Brian, D. A., and Lai, M. M., 1988, Temporal regulation of bovine coronavirus RNA synthesis, Virus Res. 9:343.

Koonin, E. V., 1991, The phylogeny of RNA-dependent RNA polymerases of positive-strand RNA viruses, I. Gen. Virol. 72:2197.

Lee, H. J., Shieh, C. K., Gorbalenya, A. E., Koonin, E. V., La-Monica, N., Tuler, J., Bagdzhadzhyan, A., and Lai, M. M., 1991, The complete sequence (22 kilobases) of murine coronavirus gene 1 encoding the putative proteases and RNA polymerase, Virology 180:567.

Leibowitz, J. L., Weiss, S. R., Paavola, E., and Bond, C. W., 1982, Cell-free translation of murine coronavirus RNA, J. Virol. 43:905.

Leibowitz, J. L., Perlman, S., Weinstock, G., DeVries, J. R., Budzilowicz, C., Weissemann, J. M., and Weiss, S. R., 1988, Detection of a murine coronavirus nonstructural protein encoded in a downstream open reading frame, Virology 164:156.

Liu, D. X., and Inglis, S. C., 1991, Association of the infectious bronchitis virus 3c protein with the virion envelope, Virology 185:911.

Liu, D. X., and Inglis, S. C., 1992, Internal entry of ribosomes on a tricistronic mRNA encoded by infectious bronchitis virus, $J$. Virol. 66:6143.

Liu, D. X., Cavanagh, D., Green, P., and Inglis, S. C., 1991, A polycistronic mRNA specified by the coronavirus infectious bronchitis virus, Virology 184:531.

Liu, D. X., Brierley, I., Tibbles, K., and Brown, T. D. K., 1994, A $100 \mathrm{~K}$ polypeptide encoded by ORF $1 \mathrm{~b}$ of the coronavirus infectious bronchitis virus is processed by ORF la products, J. Virol. 68:5772.

Lomniczi, B., and Kennedy, S. I. T., 1977, Genome of infectious bronchitis virus, J. Virol. 24:99.

Luyties, W., Bredenbeek, P. J., Noten, A. F., Horzinek, M. C., and Spaan, W. J., 1988, Sequence of mouse hepatitis virus A59 mRNA 2: indications for RNA recombination between coronaviruses and influenza $C$ virus, Virology 166:415.

Mahy, B. W. J., Siddell, S., Wege, H., and ter Meulen, V., 1983, RNA-dependent RNA polymerase activity in murine coronavirus-infected cells, J. Gen. Virol. 64:103.

Mounir, S., and Talbot, P. J., 1993, Human coronavirus OC43 RNA 4 lacks two open reading frames located downstream of the $S$ gene of bovine coronavirus, Virology 192:355.

Niesters, H. G. M., Zijderveld, A. J., Seifert, W. F., Lenstra, J. A., Bleumink-Pluym, N. M. C., Horzinek, M. C., and van der Zeijst, B. A. M., 1986, Infectious bronchitis virus RNA D encodes three potential translation products, Nucleic Acids Res. 14:3144.

Oh, C.-S., and Carrington, J. C., 1989, Identification of essential residues in potyvirus protease HC by site-directed mutagenesis, Virology 173:692.

Pachuk, C. J., Bredenbeek, P. J., Zoltick, P. W., Spaan, W. J., and Weiss, S. R., 1989, Molecular cloning of the gene encoding the putative polymerase of mouse hepatitis coronavirus, strain A59, Virology 171:141.

Page, K. W., Mawditt, K. L., and Britton, P., 1991, Sequence comparison of the 5' end of mRNA 3 from transmissible gastroenteritis virus and porcine respiratory coronavirus, I. Gen. Virol. 72:579.

Pleij, C. N., and Bosch, L., 1989, RNA Pseudoknots-structure, detection, and prediction, Methods in Enzymology 180:289. 
Raabe, T., and Siddell, S., 1989, Nucleotide sequence of the human coronavirus HCV 229E mRNA 4 and mRNA 5 unique regions, Nucleic Acids Res. 17:6387.

Raabe, T., Schelle-Prinz, B., and Siddell, S. G., 1990, Nucleotide sequence of the gene encoding the spike glycoprotein of human coronavirus HCV 229E, I. Gen. Virol. 71:1065.

Rasschaert, D., Gelfi, J., and Laude, H., 1987, Enteric coronavirus TGEV: Partial sequence of the genomic RNA, its organization and expression, Biochimie 69:591.

Schochetman, G., Stevens, R. H., and Simpson, R. W., 1977, Presence of infectious polyadenylated RNA in the coronavirus infectious bronchitis virus, Virology 77:772.

Schwarz, B., Routledge, E., and Siddell, S. G., 1990, Murine coronavirus nonstructural protein ns2 is not essential for virus replication in transformed cells, $J$. Virol. 64:4784.

Shieh, C. K., Lee, H. J., Yokomori, K., La-Monica, N., Makino, S., and Lai, M. M., 1989, Identification of a new transcriptional initiation site and the corresponding functional gene $2 \mathrm{~b}$ in the murine coronavirus RNA genome, $J$. Virol. 63:3729.

Siddell, S. G., 1983, Coronavirus JHM: Coding assignments of subgenomic mRNAs, J. Gen. Virol. 64:113.

Siddell, S. G., Wege, H., Barthel, A., and ter Meulen, V., 1981, Coronavirus JHM: Intracellular protein synthesis, J. Gen. Virol. 53:145.

Skinner, M. A., and Siddell, S. G., 1985, Coding sequence of coronavirus MHV-JHM mRNA 4, J. Gen. Virol. 66:593.

Skinner, M. A., Ebner, D., and Siddell, S. G., 1985, Coronavirus MHV-JHM mRNA 5 has a sequence arrangement which potentially allows translation of a second, downstream open reading frame, J. Gen. Virol. 66:581.

Smith, A. R., Boursnell, M. E., Binns, M. M., Brown, T. D., and Inglis, S. C., 1990, Identification of a new membrane-associated polypeptide specified by the coronavirus infectious bronchitis virus, J. Gen. Virol. 71:3.

Snijder, E. J., Wassenaar, A. L. M., and Spaan, W. J. M., 1992, The $5^{\prime}$ end of the equine arteritis virus replicase gene encodes a papain-like cysteine protease, J. Virol. 66:7040.

Soe, L. H., Shieh, C. K., Baker, S. C., Chang, M. F., and Lai, M. M., 1987, Sequence and translation of the murine coronavirus 5 '-end genomic RNA reveals the N-terminal structure of the putative RNA polymerase, $I$. Virol. 61:3968.

Somogyi, P., Jenner, A. J., Brierley, I., and Inglis, S. C., 1993, Ribosomal pausing during translation of an RNA pseudoknot, Mol. Cell. Biol. 13:6931.

Strauss, E. G., de Groot, R. J., Levinson, R., and Strauss, J. H., 1992, Identification of the active site residues in the nsP2 proteinase of Sindbis virus, Virology 191:932.

Sutou, S., Sato, S., Okabe, T., Nakai, M., and Sasaki, N., 1988, Cloning and sequencing of genes encoding structural proteins of avian infectious bronchitis virus, Virology 165:589.

ten Damm, E. B., Pleij, C. W. A., and Bosch, L., 1990, RNA pseudoknots, translational frameshifting and readthrough on viral RNAs, Virus Genes 4:121.

Thiel, V., and Siddell, S. G., 1994, Internal ribosome entry in the coding region of murine hepatitis virus mRNA 5, J. Gen. Virol. 75:3041.

Tu, C., Tzeng, T.-H., and Bruenn, J. A., 1992, Ribosomal movement impeded at a pseudoknot required for framshifting, Proc. Natl. Acad. Sci. USA 89:8636.

van der Most, R. G., Bredenbeek, P. J., and Spaan, W. J., 1991, A domain at the 3' end of the polymerase gene is essential for encapsidation of coronavirus defective interfering RNAs, $J$. Virol. 65:3219.

Vennema, H., Rossen, J. W., Wesseling, J., Horzinek, M. C., and Rottier, P. J., 1992, Genomic organization and expression of the $3^{\prime}$ end of the canine and feline enteric coronaviruses, Virology 191:134.

Wesley, R. D., Cheung, A. K., Michael, D. D., and Woods, R. D., 1989, Nucleotide sequence of coronavirus TGEV genomic RNA: Evidence for 3 mRNA species between the peplomer and matrix protein genes, Virus Res. 13:87.

Yokomori, K., and Lai, M. M., 1991, Mouse hepatitis virus S RNA sequence reveals that nonstructural proteins ns4 and ns5a are not essential for murine coronavirus replication, I. Virol. 65:5605. 
Yu, X., Bi, W., Weiss, S. R., and Leibowitz, J. L., 1994, Mouse hepatitis virus gene $5 \mathrm{~b}$ protein is a new virion envelope protein, Virology 202:1018.

Zoltick, P. W., Leibowitz, J. L., DeVries, J., Pachuk, C. J., and Weiss, S. R., 1990, Detection of mouse hepatitis virus nonstructural proteins using antisera directed against bacterial fusion proteins, in: Coronaviruses and Their Diseases, Advances in Experimental Biology and Medicine, 276 (D. Cavanagh and T. D. K. Brown, eds.), p. 291 Plenum Press, New York. 